\title{
Lie Group Analysis of Double Diffusive MHD Tangent Hyperbolic Fluid Flow over a Stretching Sheet
}

\author{
Salman Zeb, ${ }^{1}$ Suliman Khan, ${ }^{1}$ Zakir Ullah, ${ }^{1}$ Muhammad Yousaf, ${ }^{1}$ Ilyas Khan ${ }^{D},{ }^{2}$ \\ Nawa Alshammari $\mathbb{D}^{3},{ }^{3}$ Nur Alam $\mathbb{D D}^{4},{ }^{4}$ and Nawaf N. Hamadneh $\mathbb{D D}^{3}$ \\ ${ }^{1}$ Department of Mathematics, University of Malakand, Chakdara, Dir(Lower), Khyber Pakhtunkhwa, Pakistan \\ ${ }^{2}$ Department of Mathematics, College of Science Al-Zulfi, Majmaah University, Al-Majmaah 11952, Saudi Arabia \\ ${ }^{3}$ Department of Basic Sciences, College of Science and Theoretical Studies Saudi Electronic University, \\ Riyadh 11673, Saudi Arabia \\ ${ }^{4}$ Department of Mathematics, Pabna University of Science and Technology, Pabna 6600, Bangladesh
}

Correspondence should be addressed to Ilyas Khan; ilyaskhan@tdtu.edu.vn and Nur Alam; nuralam.pstu23@gmail.com

Received 27 March 2021; Revised 26 October 2021; Accepted 25 January 2022; Published 21 February 2022

Academic Editor: Mohammad Yaghoub Abdollahzadeh Jamalabadi

Copyright ( 2022 Salman Zeb et al. This is an open access article distributed under the Creative Commons Attribution License, which permits unrestricted use, distribution, and reproduction in any medium, provided the original work is properly cited.

\begin{abstract}
In this study, we have used Lie group analysis procedure to propose a novel model for transforming the governing equations of double diffusive MHD hyperbolic tangent fluid flow model into a system of nonlinear ordinary differential equations (ODEs). The solution of these equations is then investigated numerically by employing Shooting method. We also reported and presented our results graphically illustrating the results and analysis of physical parameters on concentration, velocity, and temperature profiles and on other physical quantities present in the flow model. The results show that fluid temperature increases with rise in the modified Dufour and velocity slip parameters whereas opposite behavior is observed for thermal slip parameter. Moreover, the Nusselt number declines with enhanced values of modified Dufour parameter whereas its opposite effect has been observed for Dufour-solutal Lewis number and Prandtl number.
\end{abstract}

\section{Introduction}

The magnetohydrodynamic (MHD) flow over a stretching sheet has numerous industrial and manufacturing applications, which include polymer extrusion, continuous casting of metals, petroleum industries, and electrical power generators. Due to its large-scale applications, many researchers attempted to study and analyze the solutions of differential equations describing boundary layer and MHD fluid flow problems along a stretching sheet. The pioneering work in this regard is carried out by Sakiadis [1], who studied the boundary layer equations over continuous solid surfaces. Later on, Crane [2] analyzed laminar boundary layer steady flow caused by a linear stretching sheet. Pavlov [3] obtained exact solution of momentum equation for MHD fluid flow along a stretching sheet. Since then, a number of researchers studied the stretching sheet problems by considering various aspects [4-8]. The investigation of numerically solving the heat transfer of MHD fluid flow in a stretching cylinder is attributed to Ishak et al. [9]. Mukhopadhyay [10] discussed the slip flow influence of the magnetic field towards a stretchable cylindrical surface. Zaimi and Ishak [11] presented the analysis of heat transfer along a stretching vertical sheet by considering partial slip conditions on stagnationpoint flow. Bhojappa and Zeb [12] proposed the aspect of chemical reaction on steady 3D Maxwell nanofluid through a stretched sheet. They noticed that growing values of chemical reaction enhance the concentration distribution. Some other researchers recently studied and reported the dynamics of MHD boundary layer flow problems over the cylindrical surfaces. Interested readers may refer to [13-17] for more details.

The applications of non-Newtonian fluids in different fields of science and engineering have gained considerable attention of researchers for investigating their thermophysical aspects. These fluids are appropriate in chemical, 
pharmaceutical, and other industrial sectors. However, the study of non-Newtonian fluids poses a number of challenges. These include the existence of highly nonlinear governing equations in comparison with equations for Newtonian fluids and the nonexistence of a single constitutive equation, which explicitly describes these fluids due to their diverse nature. Keeping in view these issues, researchers have suggested a variety of fundamental equations for evaluating the physical aspects of non-Newtonian fluids. An important non-Newtonian model is tangent hyperbolic fluid, which is utilized in a number of industrial processes and laboratory experiments. The tangent hyperbolic model has been studied from different perspectives by various researchers [18-24]. The authors in [25] explored the peristaltic MHD tangent hyperbolic fluid flow by taking into account an inclined asymmetric channel having partial slip conditions. The effect of double diffusive convection on stagnation-point flow for a model of hyperbolic tangent nanofluid was inspected in [26] where the authors revealed that Brownian motion variable decreases the concentration curves and at the same time increases the temperature. Rehman et al. [27] deliberated the influence of heat generation and magnetic parameter for a stretching cylindrical surface by considering a model of thermally stratified tangent hyperbolic fluid. Zakir et al. [28] appraised the impact of stretching parameter on the tangent hyperbolic fluid model with suction/injection. They reported the enhancement of velocity distribution for growing values of stretching parameter.

Lie group analysis is a technique valuable for investigation of nonlinear partial differential equations. The development of this method can be seen in Lie and Ackerman's work [29] whereas for the unification of known exact integration techniques considering differential equations, refer to [30]. Many researchers studied various fluid flow problems under different conditions using the Lie group analysis method [31-36]. Kandasamy et al. [37] used the Lie group transformation method for analyzing an electrically conducting steady incompressible flow along a vertical stretchable sheet. In [38], the authors explored the free convective flow of a nanofluid by considering a porous media on a chemically reacting horizontal plate and obtained its Lie group solution. Ullah and Zaman [39] studied Lie group analysis of the MHD hyperbolic tangent slip flow model along a stretchable sheet. Ahmad et al. [40] deliberated characteristics of heat transfer and flow behavior along a shrinking sheet considering the effects of thermal slip conditions and magnetic parameter.

In this work, we investigated numerical simulation of the double diffusive MHD hyperbolic tangent fluid flow model. We found new similarity transformations using Lie group analysis procedure, which transformed the nonlinear governing equations into a system of nonlinear ODEs. Its numerical solution is then investigated by employing the Shooting method in Mathematica software. We also carried out the analysis of different parameters including Weissenberg number, Lewis number, Prandtl number, Brownian motion, Hartmann number, power law index, source/sink parameter, thermophoresis on temperature, and velocity/ concentration profiles. All the important findings are illustrated graphically.

We organized this paper as follows. In Section 2, the problem is formulated under certain assumptions. In Section 3 , similarity transformations are obtained using Lie group analysis procedure, which gives us nonlinear ODEs. In Section 4, the numerical results, graphical illustrations, and discussion are presented. In Section 5, conclusion of the proposed work is drawn.

\section{Mathematical Model}

In this work, we consider a double diffusive convective MHD incompressible flow for a tangent hyperbolic fluid model and assume that the flow generation is anticipated from linear stretching. Further, we assume that the flow is bounded to the region $y>0$ and coincident with the plane $y=0$ (see Figure 1). We define the extra stress tensor for hyperbolic tangent fluid model as shown in following equation $[25,41]$.

$$
\bar{S}=\left[\eta_{\infty}+\left(\eta_{0}+\eta_{\infty}\right) \tanh (\Gamma \overline{\dot{\gamma}})^{n}\right] \overline{\dot{\gamma}},
$$

where $n$ is the flow behavior index, $\eta_{\infty}$ stands for infinite shear rate viscosity, $\Gamma$ represents time dependent material constant, and $\eta_{0}$ appears for zero shear rate viscosity. The term $\bar{\gamma}$ in (1) is defined as given in the following equation:

$\bar{\gamma}=\sqrt{\frac{1}{2} \Sigma_{i} \Sigma_{j} \bar{\gamma}_{\mathrm{ij}}} \bar{\gamma}_{\mathrm{ji}}=\sqrt{\frac{1}{2} \Pi}$, where $\Pi=\frac{1}{2} \operatorname{tr}\left(\operatorname{grad} V+\left(\operatorname{grad} V^{T}\right)\right)^{2}$.

Incorporating $\Gamma \bar{\gamma}<1$ and $\eta_{\infty}=0$ due to shear thinning characteristics of the fluid flow, the modified form of (1) implies

$$
\bar{S}=\eta_{0}[(1+n(\Gamma \bar{\gamma}-1)] \overline{\dot{\gamma}} .
$$

Under the assumptions mentioned above, we have the continuity equation, i.e., as follows:

$$
\frac{\partial u}{\partial x}+\frac{\partial v}{\partial y}=0
$$

The equation of momentum as of [28] is given as follows:

$$
u \frac{\partial u}{\partial x}+v \frac{\partial u}{\partial y}=v(1-n) \frac{\partial^{2} u}{\partial y^{2}}+\sqrt{2} v n \Gamma\left(\frac{\partial u}{\partial y}\right) \frac{\partial^{2} u}{\partial y^{2}}-\frac{\sigma B^{2}}{\rho} u .
$$

The energy equation as of [42] is given as follows:

$$
u \frac{\partial T}{\partial x}+v \frac{\partial T}{\partial y}=\frac{k}{\rho c_{p}} \frac{\partial^{2} T}{\partial y^{2}}+\frac{Q_{0}}{\rho c_{p}}\left(T-T_{\infty}\right)+D_{T C} \frac{\partial^{2} C}{\partial y^{2}} .
$$
follows:

The concentration equation as of [42] is expressed as

$$
u \frac{\partial C}{\partial x}+v \frac{\partial C}{\partial y}=D_{\mathrm{sm}} \frac{\partial^{2} C}{\partial y^{2}}+D_{\mathrm{CT}} \frac{\partial^{2} T}{\partial y^{2}} .
$$

In these governing equations, the terms $D_{\mathrm{sm}}, D_{\mathrm{CT}}$, and $B$ represent the solutal diffusivity of porous medium, diffusivity of Soret type, and applied uniform magnetic field, 


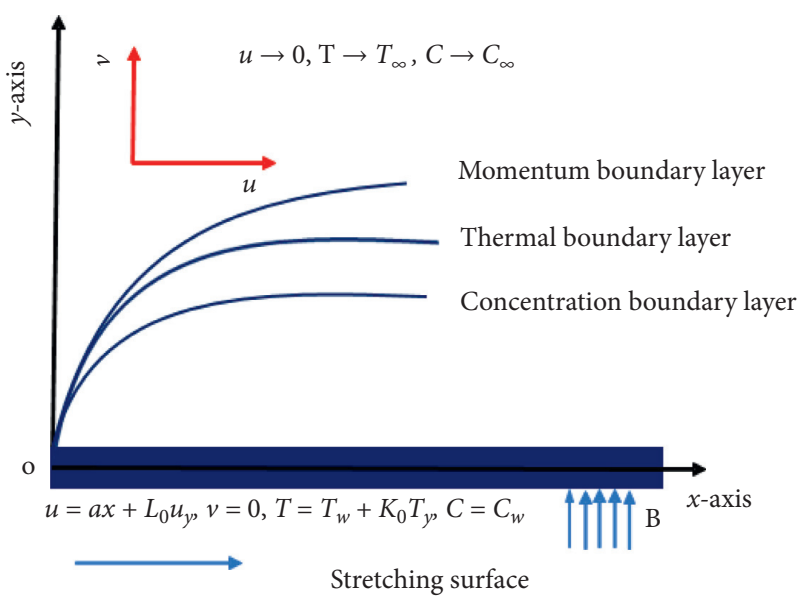

Figure 1: Flow configuration.

respectively. Similarly, $\nu$ stands for kinematic fluid viscosity, $\rho$ denotes the fluid density, and $\sigma$ stands for electrical conductivity of the fluid. Also, velocity components along $(x, y)$ coordinate system are represented by $(u, v)$. The term $c_{p}$ represents the specific heat, $Q_{0}$ stands for volumetric rate of the heat generation, and $k$ represents thermal conductivity. Moreover, the terms $T, T_{w}, T_{\infty}$, and $C$ represent the temperature, temperature at the wall, the free stream temperature, and concentration, respectively.

The appropriate boundary conditions associated with Equations (4)-(7) are identified as follows:

$$
\begin{aligned}
& \text { at } y=0, u=a x+L_{0} \frac{\partial u}{\partial y}, v=0, T=T_{w}+K_{0} \frac{\partial T}{\partial y}, C=C_{w}, \\
& \text { as } y \longrightarrow \infty, u \longrightarrow 0, T \longrightarrow T_{\infty}, C \longrightarrow C_{\infty},
\end{aligned}
$$

where $K_{0}$ stands for thermal slip factor, $L_{0}$ stands for velocity slip factor, and $a$ stands for the stretching rate. For requirements of nondimensionalized form of Equations (4)-(7) and (8), we consider the following:

$$
\bar{u}=\frac{u}{\sqrt{a v}}, \bar{x}=\sqrt{\frac{a}{v}} x, \bar{v}=\frac{v}{\sqrt{a v}}, \bar{y}=\sqrt{\frac{a}{v}} y, \phi=\frac{C-C_{\infty}}{C_{w}-C_{\infty}}, \theta=\frac{T-T_{\infty}}{T_{w}-T_{\infty}},
$$

which shows dimensionless quantities. After simplification, (4) implies the following:

$$
\frac{\partial u}{\partial x}+\frac{\partial v}{\partial y}=0
$$

Similarly, (5) implies the following:

$u \frac{\partial u}{\partial x}+v \frac{\partial u}{\partial y}=(1-n) \frac{\partial^{2} u}{\partial y^{2}}+\sqrt{2} n \Gamma a\left(\frac{\partial u}{\partial y}\right) \frac{\partial^{2} u}{\partial y^{2}}-\frac{\sigma B^{2}}{\rho a} u$.

Likewise, (6) implies the following:

$$
u \frac{\partial \theta}{\partial x}+v \frac{\partial \theta}{\partial y}=\frac{k}{\mu c_{p}} \frac{\partial^{2} \theta}{\partial y^{2}}+\frac{Q_{0}}{\rho c_{p} a} \theta+\frac{D_{\mathrm{TC}}}{v} \frac{\left(C_{w}-C_{\infty}\right)}{\left(T_{w}-T_{\infty}\right)} \frac{\partial^{2} \phi}{\partial y^{2}},
$$

and (7) becomes

$$
u \frac{\partial \phi}{\partial x}+v \frac{\partial \phi}{\partial y}=\frac{D_{\mathrm{sm}}}{v} \frac{\partial^{2} \phi}{\partial y^{2}}+\frac{D_{\mathrm{CT}}}{v}\left(\frac{T_{w}-T_{\infty}}{C_{w}-C_{\infty}}\right) \frac{\partial^{2} \theta}{\partial y^{2}} .
$$

From boundary conditions in (8), we have

$$
\begin{aligned}
& \text { at } y=0, u=x+\sqrt{\frac{a}{v}} L_{0} \frac{\partial u}{\partial y}, v=0, \theta=1+\sqrt{\frac{a}{v}} K_{0} \frac{\partial \theta}{\partial y}, \phi=1, \\
& \text { as } y \longrightarrow \infty, u \longrightarrow 0, \theta \longrightarrow 0, \phi \longrightarrow 0,
\end{aligned}
$$

where for brevity, we removed bars from the equations above.

\section{Scaling Transformations}

Before applying scaling transformations, we first introduce the stream function $\psi$ as follows:

$$
\begin{aligned}
& u=\frac{\partial \psi}{\partial y}, \\
& v=-\frac{\partial \psi}{\partial x},
\end{aligned}
$$

and put it into (10)-(13) and (14) so Equation (10) is satisfied automatically and Equation (11) is transformed into Equation (15). 


$$
\left(\frac{\partial \psi}{\partial y} \frac{\partial^{2} \psi}{\partial x \partial y}-\frac{\partial \psi}{\partial x} \frac{\partial^{2} \psi}{\partial y^{2}}\right)=(1-n) \frac{\partial^{3} \psi}{\partial y^{3}}+\sqrt{2} n \Gamma a\left(\frac{\partial^{2} \psi}{\partial y^{2}}\right) \frac{\partial^{3} \psi}{\partial y^{3}}-\frac{\sigma B^{2}}{\rho a} \frac{\partial \psi}{\partial y}
$$

Similarly, (12) becomes the following:

$$
\left(\frac{\partial \psi}{\partial y} \frac{\partial \theta}{\partial x}-\frac{\partial \psi}{\partial x} \frac{\partial \theta}{\partial y}\right)=\frac{k}{\mu c_{p}} \frac{\partial^{2} \theta}{\partial y^{2}}+\frac{Q_{0}}{\rho c_{p} a} \theta+\frac{D_{\mathrm{TC}}}{v} \frac{\left(C_{w}-C_{\infty}\right)}{\left(T_{w}-T_{\infty}\right)} \frac{\partial^{2} \phi}{\partial y^{2}} .
$$

Equation (13) becomes the following:

$$
\left(\frac{\partial \psi}{\partial y} \frac{\partial \phi}{\partial x}-\frac{\partial \psi}{\partial y} \frac{\partial \phi}{\partial y}\right)=\frac{D_{\mathrm{sm}}}{v} \frac{\partial^{2} \phi}{\partial y^{2}}+\frac{D_{\mathrm{CT}}}{v}\left(\frac{T_{w}-T_{\infty}}{C_{w}-C_{\infty}}\right) \frac{\partial^{2} \theta}{\partial y^{2}},
$$

and its associated boundary conditions become as shown in the following:

at $y=0, \frac{\partial \psi}{\partial x}=0, \frac{\partial \psi}{\partial y}=x+\sqrt{\frac{a}{\nu}} L_{0} \frac{\partial^{2} \psi}{\partial y^{2}}, \theta=1+\sqrt{\frac{a}{\nu}} K_{0} \frac{\partial \theta}{\partial y}, \phi=1$, as $y \longrightarrow \infty, \frac{\partial \psi}{\partial y} \longrightarrow 0, \theta \longrightarrow 0, \phi \longrightarrow 0$.
Let $\varepsilon$ be the small parameter of the scaling transformation. Then, transformation $\mathrm{F}$ (a special form of Lie group analysis) is considered as given in the following:

$$
\begin{aligned}
\mathrm{F}: x^{*} & =x e^{\varepsilon r_{1}}, y^{*}=y e^{\varepsilon r_{2}}, \psi^{*}=\psi e^{\varepsilon r_{3}}, \\
\theta^{*} & =\theta e^{\varepsilon r_{4}}, \phi^{*}=\phi e^{\varepsilon r_{5}}, \Gamma^{*}=\Gamma e^{\varepsilon r_{6}},
\end{aligned}
$$

where $r_{1}, r_{2}, \ldots, r_{6}$ are arbitrary real numbers. The pointtransformation given in (20) transformed the co-ordinates $(x, y, \psi, \theta, \phi, \Gamma)$ into $\left(x^{*}, y^{*}, \psi^{*}, \theta^{*}, \phi^{*}, \Gamma^{*}\right)$.

Therefore, utilizing Equation (20), Equation (16) results in the following:

$$
\begin{gathered}
e^{\varepsilon\left(r_{1}+2 r_{2}-2 r_{3}\right)}\left(\frac{\partial \psi^{*}}{\partial y^{*}} \frac{\partial^{2} \psi^{*}}{\partial x^{*} \partial y^{*}}-\frac{\partial \psi^{*}}{\partial x^{*}} \frac{\partial^{2} \psi^{*}}{\partial y^{* 2}}\right)=e^{\varepsilon\left(3 r_{2}-r_{3}\right)}(1-n) \frac{\partial^{3} \psi^{*}}{\partial y^{* 3}} \\
+e^{\varepsilon\left(5 r_{2}-2 r_{3}-r_{6}\right)}\left(\sqrt{2} n \Gamma^{*} a\left(\frac{\partial^{2} \psi^{*}}{\partial y^{*}}\right) \frac{\partial^{3} \psi^{*}}{\partial y^{* 3}}\right)-\frac{\sigma B^{2}}{\rho a} e^{\varepsilon\left(r_{2}-r_{3}\right)} \frac{\partial \psi^{*}}{\partial y^{*}}
\end{gathered}
$$

Equation (17) implies the following:

$$
\begin{aligned}
e^{\varepsilon\left(r_{1}+r_{2}-r_{3}-r_{4}\right)}\left(\frac{\partial \psi^{*}}{\partial y^{*}} \frac{\partial \theta^{*}}{\partial x^{*}}-\frac{\partial \psi^{*}}{\partial x^{*}} \frac{\partial \theta^{*}}{\partial y^{*}}\right) \\
=e^{\varepsilon\left(2 r_{2}-r_{4}\right)} \frac{k}{\mu c_{p}} \frac{\partial^{2} \theta^{*}}{\partial y^{* 2}} \\
+\frac{Q_{0}}{\rho c_{p} a} e^{-\varepsilon r_{4}} \theta^{*}+e^{\varepsilon\left(2 r_{2}-r_{5}\right)} \frac{D_{\mathrm{TC}}}{v} \frac{\left(C_{w}-C_{\infty}\right)}{\left(T_{w}-T_{\infty}\right)} \frac{\partial^{2} \phi^{*}}{\partial y^{* 2}},
\end{aligned}
$$

and (18) is transformed into the following:

$$
\begin{aligned}
& e^{\varepsilon\left(r_{1}+r_{2}-r_{3}-r_{5}\right)}\left(\frac{\partial \psi^{*}}{\partial y^{*}} \frac{\partial \phi^{*}}{\partial x^{*}}-\frac{\partial \psi^{*}}{\partial x^{*}} \frac{\partial \phi^{*}}{\partial y^{*}}\right) \\
& =e^{\varepsilon\left(2 r_{2}-r_{5}\right)} \frac{D_{\mathrm{sm}}}{v} \frac{\partial^{2} \phi^{*}}{\partial y^{* 2}} \\
& +e^{\varepsilon\left(2 r_{2}-r_{4}\right)} \frac{D_{\mathrm{CT}}}{v}\left(\frac{T_{w}-T_{\infty}}{C_{w}-C_{\infty}}\right) \frac{\partial^{2} \theta^{*}}{\partial y^{* 2}}
\end{aligned}
$$

If the exponent of these transformed systems of equations satisfies the following equations:(26)

$$
\begin{aligned}
& r_{1}+r_{2}-2 r_{3}=3 r_{2}-r_{3}=5 r_{2}-2 r_{3}-r_{6}=r_{2}-r_{3}, \\
& r_{1}+r_{2}-r_{3}-r_{4}=2 r_{2}-r_{4}=-r_{4}=2 r_{2}-r_{5}, \\
& r_{1}+r_{2}-r_{3}-r_{5}=2 r_{2}-r_{5}=2 r_{2}-r_{4},
\end{aligned}
$$

then Equations (21)-(23) will remain invariant under the transformation $\mathrm{F}$.

Next, by solving Equations (24)-(26) simultaneously, we get

$$
\begin{aligned}
& r_{1}=r_{1}, \\
& r_{2}=0, \\
& r_{3}=r_{1}, \\
& r_{4}=0, \\
& r_{5}=0, \\
& r_{6}=-r_{1} .
\end{aligned}
$$

Putting (27) into the scaling transformations in (20), we obtain 


$$
\mathrm{F}: x^{*}=\mathrm{xe}^{\varepsilon r_{1}}, y^{*}=y, \psi^{*}=\psi e^{\varepsilon r_{1}}, \theta^{*}=\theta, \phi^{*}=\phi, \Gamma^{*}=\Gamma e^{-\varepsilon r_{1}} .
$$

By utilizing Taylor's series expansion on transformations in (28), we get the characteristic equations as

$$
\frac{\mathrm{d} x}{\mathrm{xr}_{1}}=\frac{\mathrm{d} y}{0}=\frac{d \psi}{\psi r_{1}}=\frac{d \theta}{0}=\frac{d \phi}{0}=\frac{d \Gamma}{-\Gamma r_{1}} .
$$

From (29), one can easily obtain new similarity transformations as given in the following:

$$
y=\eta, \phi=\phi(\eta), \theta=\theta(\eta), \psi=\operatorname{xf}(\eta), \Gamma=x^{-1} \Gamma_{0} .
$$

Putting quantities given in (30) into equations (16)-(18) and in boundary conditions specified in (19), we obtain

$$
(1-n) f^{\prime \prime \prime}+\mathrm{nW}_{e}\left(f^{\prime \prime}\right) f^{\prime \prime \prime}+f^{\prime \prime} f-\left(f^{\prime}\right)^{2}-M^{2} f^{\prime}=0,
$$

where $n$ stands for power law index, $M^{2}=\sigma B^{2} / \rho a$ stands for Hartmann number, and $W_{e}=\sqrt{2} \Gamma a$ is the Weissenberg number.

$$
\theta^{\prime \prime}+\operatorname{Pr}\left(f \theta^{\prime}+Q \theta\right)+\operatorname{Pr} N_{d} \phi^{\prime \prime}=0
$$

where $\operatorname{Pr}=\mu c_{p} / k$ is the Prantdl number, $\mathrm{Nd}=D_{\mathrm{CT}} / \nu\left(C_{w}-\right.$ $\left.C_{\infty}\right) /\left(T_{w}-T_{\infty}\right)$ is modified Dufour parameter, and $Q=$ $Q_{0} / \rho c_{p} a$ is the source/sink parameter.

$$
\phi^{\prime \prime}+\operatorname{Pr} \operatorname{Le}\left(f \phi^{\prime}\right)+L_{d} \theta^{\prime \prime}=0,
$$

where Le $=k / \rho c_{p} D_{\text {sm }}$ represents Lewis number, $\mathrm{Ld}=D_{\mathrm{CT}} / D_{\mathrm{sm}}\left(T_{w}-T_{\infty} / C_{w}-C_{\infty}\right)$ stands for Dufour-solutal Lewis number, and

$$
\begin{aligned}
& \text { at } \eta=0, f^{\prime}=1+\alpha f^{\prime \prime}(0), f=0, \phi=1, \theta=1+b \theta^{\prime}(0), \\
& \text { as } \eta \longrightarrow 0, f^{\prime} \longrightarrow 0, \phi \longrightarrow 0, \theta \longrightarrow 0,
\end{aligned}
$$

where $\alpha=\sqrt{a / v} L_{0}$ stands for velocity slip parameter and $b=$ $\sqrt{a / \nu} K_{0}$ represents thermal slip parameter. The prime in these equations denotes differentiation with respect to $\eta$.

Hence, it is required to solve equations (31)-(33) subject to the conditions in (34).

Here, we define equations (35)-(37).

$$
\begin{aligned}
C_{f} & =\frac{\tau_{w}}{\rho(\mathrm{ax})^{2}}, \\
\mathrm{Sh}_{x} & =\frac{\mathrm{xh}_{m}}{D_{\mathrm{sm}}\left(C_{w}-C_{\infty}\right)}, \\
\mathrm{Nu}_{x} & =\frac{\mathrm{xq}_{w}}{k\left(T_{w}-T_{\infty}\right)},
\end{aligned}
$$

where $C_{f}$ stands for skin friction coefficient, $\mathrm{Sh}_{x}$ is the local Sherwood number, $\mathrm{Nu}_{x}$ stands for the local Nusselt number, and

$$
\begin{aligned}
& h_{m}=-D_{\mathrm{sm}}\left(\frac{\partial C}{\partial y}\right), \\
& q_{w}=-k\left(\frac{\partial T}{\partial y}\right), \\
& \tau_{w}=\mu\left[(1-n) \frac{\partial u}{\partial y}+\frac{n \Gamma}{\sqrt{2}}\left(\frac{\partial u}{\partial y}\right)^{2}\right],
\end{aligned}
$$

where $h_{m}$ is the mass flux, $q_{w}$ stands for the heat transfer from the plate, and $\tau_{w}$ represents the skin friction. Substituting (9), (30), and (36) into (35), we obtain its dimensionless form as follows:

$$
\operatorname{Re}^{1 / 2} C_{f}=(1-n) f^{\prime \prime}(0)+\frac{n}{2} \mathrm{We}\left(f^{\prime \prime}(0)\right)^{2}, \operatorname{Re}^{-1 / 2} \mathrm{Nu}_{x}=-\theta^{\prime}(0), \operatorname{Re}^{-1 / 2} S h_{x}=-\phi^{\prime}(0)
$$

where the local Reynolds number is represented as $\operatorname{Re}=\mathrm{ax}^{2} / \nu$.

\section{Numerical Results and Discussion}

Here, the Shooting method is utilized to numerically solve the governing nonlinear system of ODEs (30)-(33). For coding purpose, MATHEMATICA 10 software is used. A small step size $(\Delta \eta=0.0001)$ along with convergence criteria is taken upto $10^{-7}$. We used a variety of values of the controlling parameters describing the flow problem for numerical simulations. We have also compared our proposed scheme in Table 1 for the skin friction coefficient with Zakir and Zaman [39] and Noreen Sher Akbar et al. [25]. We carried out the comparison by keeping $\alpha$ (the velocity slip parameter) absent. The results show excellent agreement and demonstrate accuracy for each considered value.

The graphical representations of the numerical results for different governing parameters influencing the heat transfer and flow behavior of the proposed model are depicted in Figures 2-9.

Figures 2(a)-2(d) depict the behavior of $W e, \alpha, M$, and $n$ on velocity distribution, respectively. It is evident that a decline in velocity and momentum boundary layer thickness occurs with growing intensity of $M$. This behavior is owing to the occurrence of Lorentz force, which causes retardation and opposes the fluid flow. The thickness of the hydrodynamic boundary layer declines with growing $n$ values. The velocity profile reduces showing more resistance to the flow for each increasing value of $W e$ due to increase in relaxation 
TABLE 1: Comparison of skin friction coefficient values.

\begin{tabular}{|c|c|c|c|c|c|c|c|c|c|c|}
\hline \multirow{2}{*}{$n \downarrow$} & \multirow{2}{*}{$M \downarrow$} & \multicolumn{3}{|c|}{ Akber et al. [21] } & \multicolumn{3}{|c|}{ Zakir and Zaman [39] } & \multicolumn{3}{|c|}{ Results of the present study } \\
\hline & & $W_{e}=0$ & $W_{e}=0.3$ & $W_{e}=0.5$ & $W_{e}=0$ & $W_{e}=0.3$ & $W_{e}=0.5$ & $W_{e}=0$ & $W_{e}=0.3$ & $W_{e}=0.5$ \\
\hline 0.0 & 0 & 1 & 1 & 1 & 1 & 1 & 1 & 1.0014 & 1.0014 & 1.0014 \\
\hline 0.1 & 0 & 0.94868 & 0.94248 & 0.93826 & 0.94868 & 0.94248 & 0.93826 & 0.949674 & 0.943456 & 0.939227 \\
\hline 0.2 & 0 & 0.89442 & 0.88023 & 0.87026 & 0.89442 & 0.88023 & 0.87026 & 0.895092 & 0.880871 & 0.870891 \\
\hline 0.3 & 0.5 & 1.02472 & 0.98804 & 0.96001 & 1.02472 & 0.98804 & 0.96001 & 1.02472 & 1.07482 & 1.06011 \\
\hline 0.3 & 1.0 & 1.18322 & 1.13454 & 1.09616 & 1.18322 & 1.13454 & 1.09616 & 1.18322 & 1.23764 & 1.09616 \\
\hline 0.3 & 1.5 & 1.32288 & 1.26193 & 1.21235 & 1.32288 & 1.26193 & 1.21235 & 0.33288 & 1.26193 & 1.21235 \\
\hline
\end{tabular}


(a)

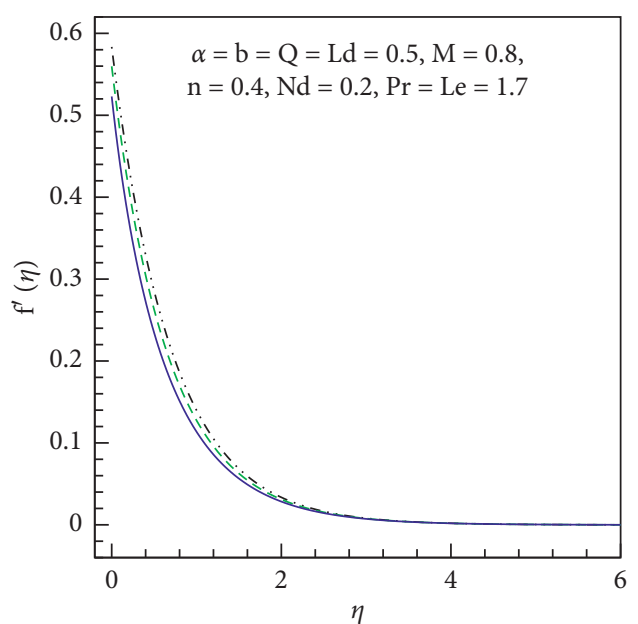

(b)

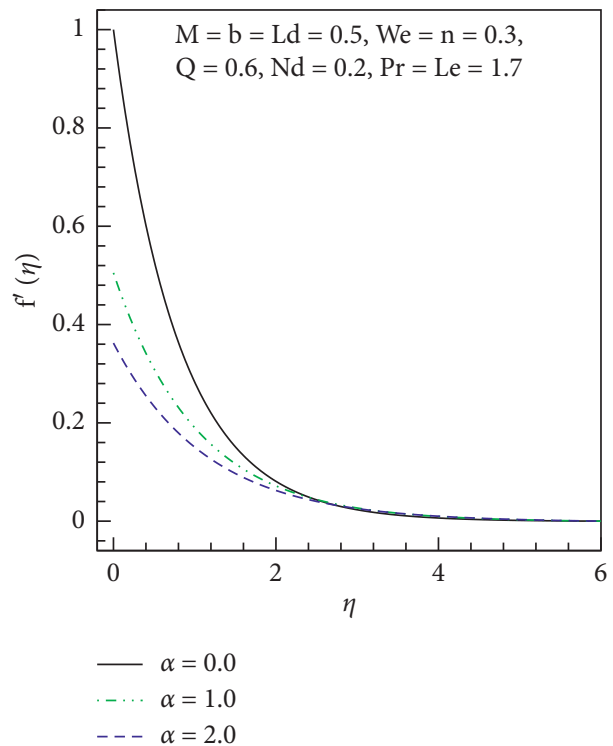

(c)

(d)

FIgURE 2: Variations in velocity profiles for $M, n$, We, and $\alpha$. 

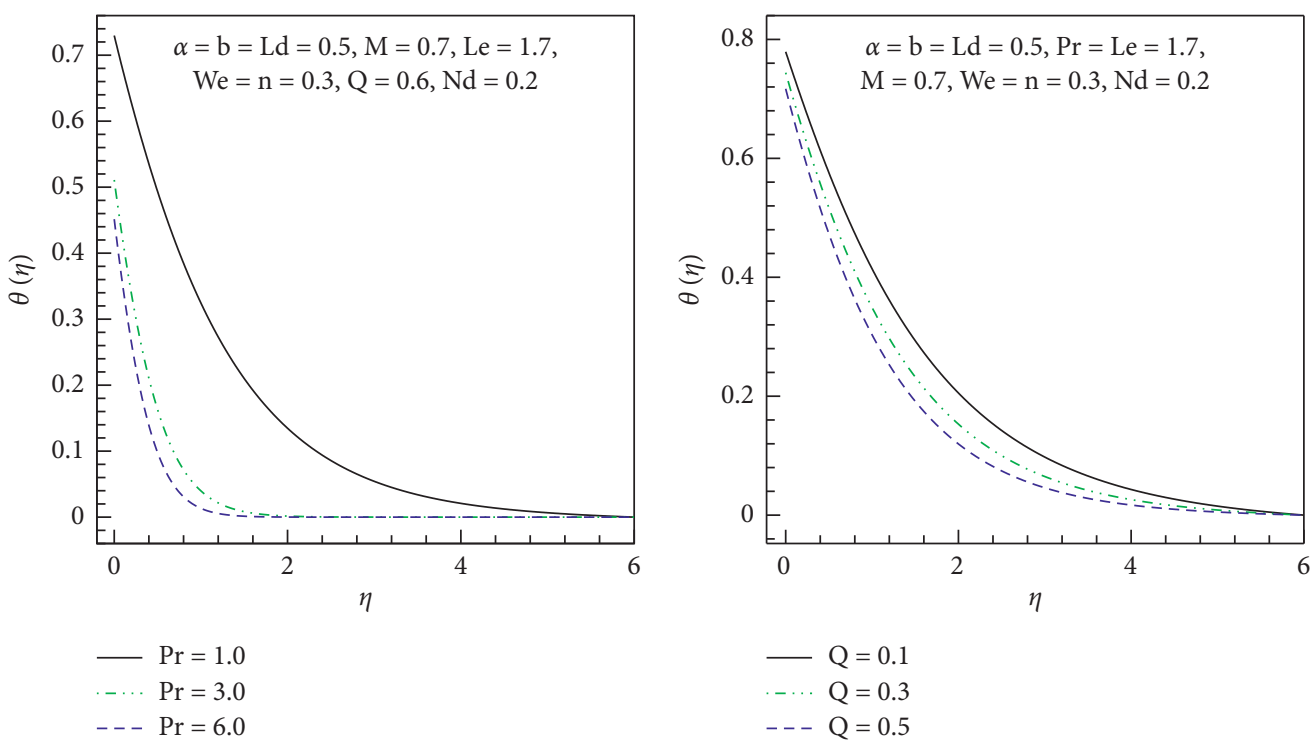

(a)

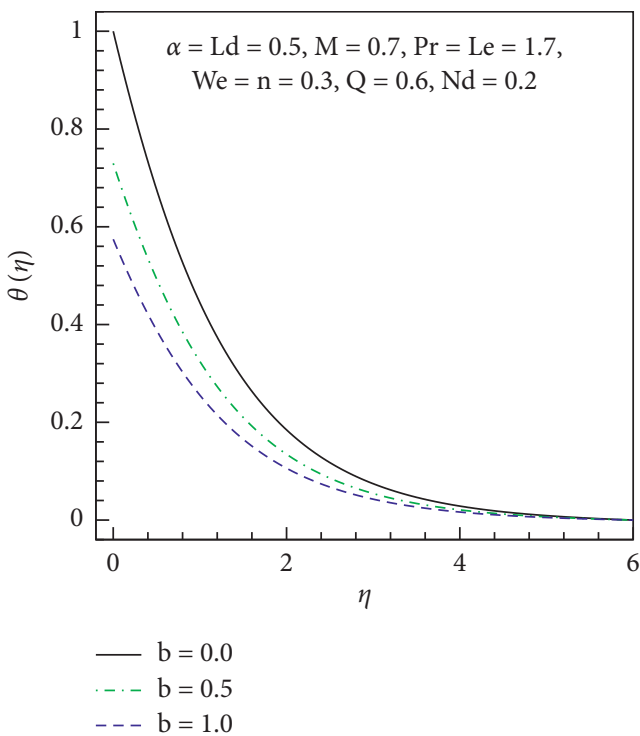

(b)

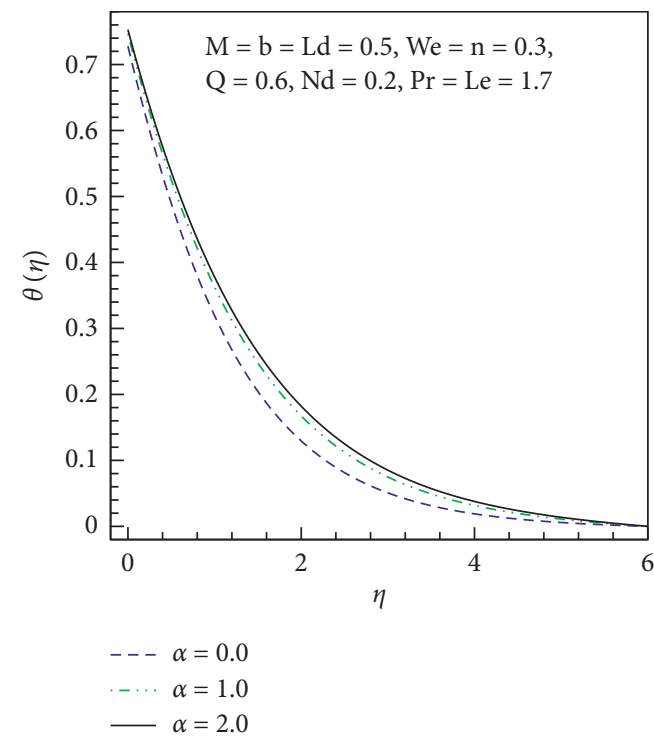

(c)

(d)

Figure 3: Variations in temperature profiles for $\operatorname{Pr}, Q, b$, and $\alpha$.

time. In addition to this, we also observe that velocity profile reduces with increase in $\alpha$.

Figures 3(a) and 4(b) show the effects of $\operatorname{Pr}, \mathrm{Q}, \alpha, b, \mathrm{Nd}$, and $n$ on temperature profile, respectively. Here, the temperature profile reduces and a rapid decline occurs in thermal boundary layer for growing Pr values. The skin parameter $Q$ has the same behavior on temperature function as of Figure 3(a). The temperature distribution reduces with rising $b$ values. The qualitative behavior of $\alpha$ on the temperature profile is opposite to the quantities that are shown in Figure 3(c). Moreover, the qualitative behavior of Figures 4(a) and 4(b) is similar.

In Figures 5(a) and 6(b), we can see the effects of Le, Ld, $n, b, \alpha$, and $M$ on concentration profile of the flow. The concentration profile reduces with increase in Le. It is attributed to the reason that mass diffusivity reduces by increasing Le. The concentration function $\phi(\eta)$ and the concentration boundary layer thickness increase by enhancing Ld. The concentration profile increases for increasing values of $n$ and $\alpha$ whereas for $b$ it has an opposite effect. Moreover, the concentration function and thickness of boundary layer observe a strict rise by increasing $M$, which are depicted in Figure 6(b).

The skin friction coefficient reduces for augmented values of $n$ and $\alpha$ as shown in Figure 7(a). Moreover, less resistance to the flow is depicted for increasing values of We whereas it shows an increasing trend for $M$ as illustrated in Figure 7(b).

The heat transfer rate enhances for increasing $\mathrm{Pr}$ whereas $\mathrm{Nd}$ has an opposite effect on it as shown in 


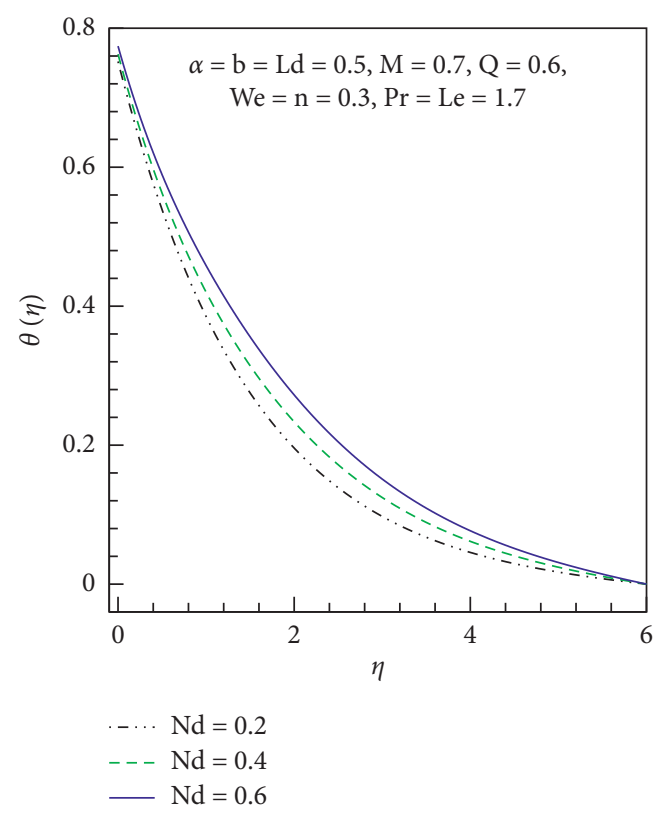

(a)

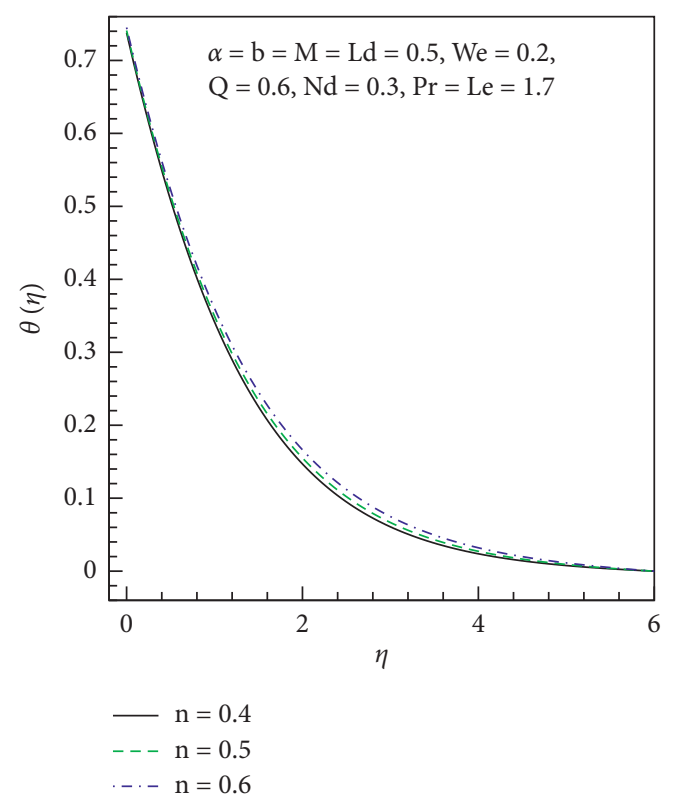

(b)

FIgURE 4: Variations in temperature profiles for $\mathrm{Nd}$ and $n$.
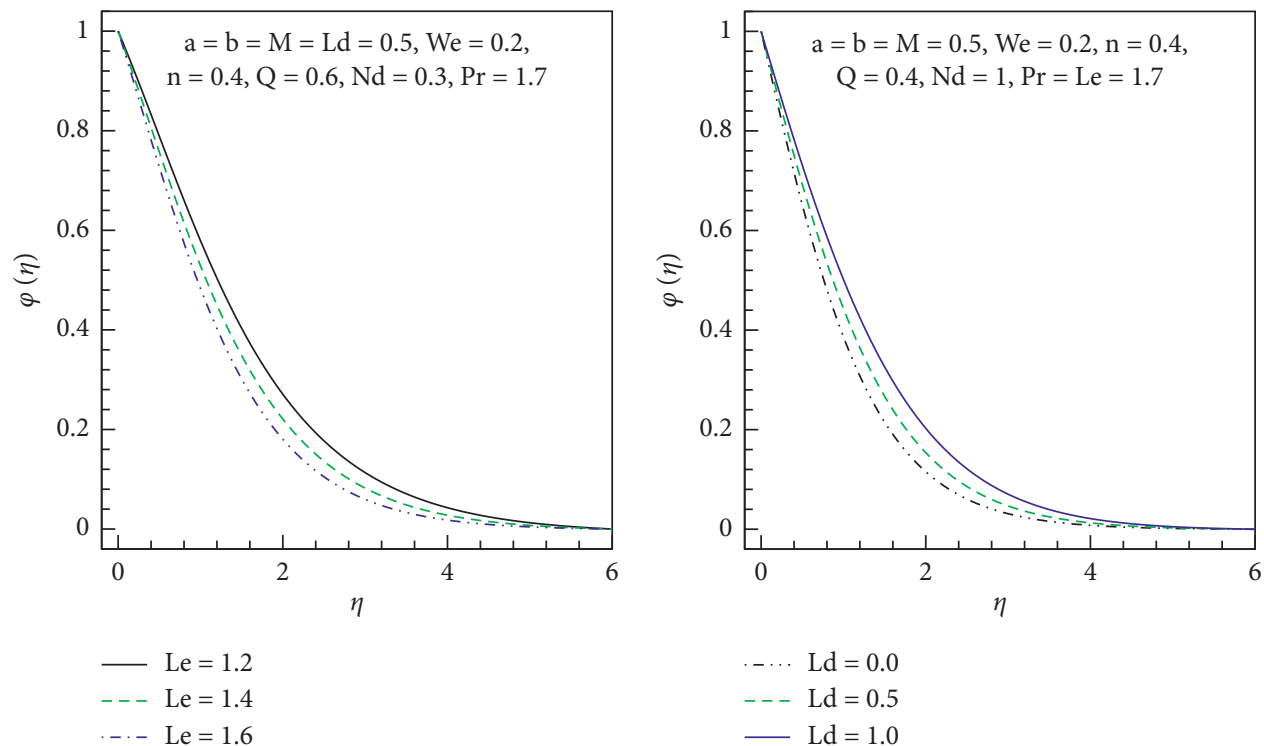

(a)

(b)

Figure 5: Continued. 


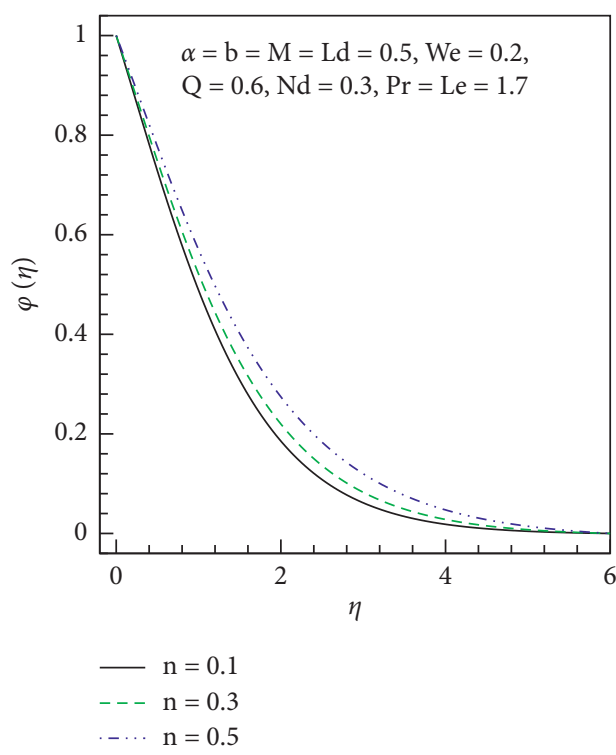

(c)

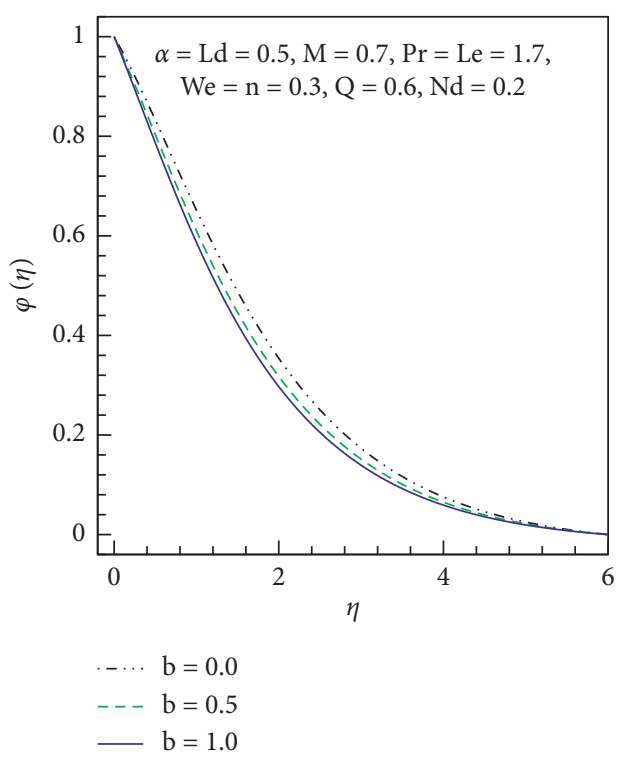

(d)

Figure 5: Variations in concentration profiles for Le, Ld, $n$, and $b$.



(a)

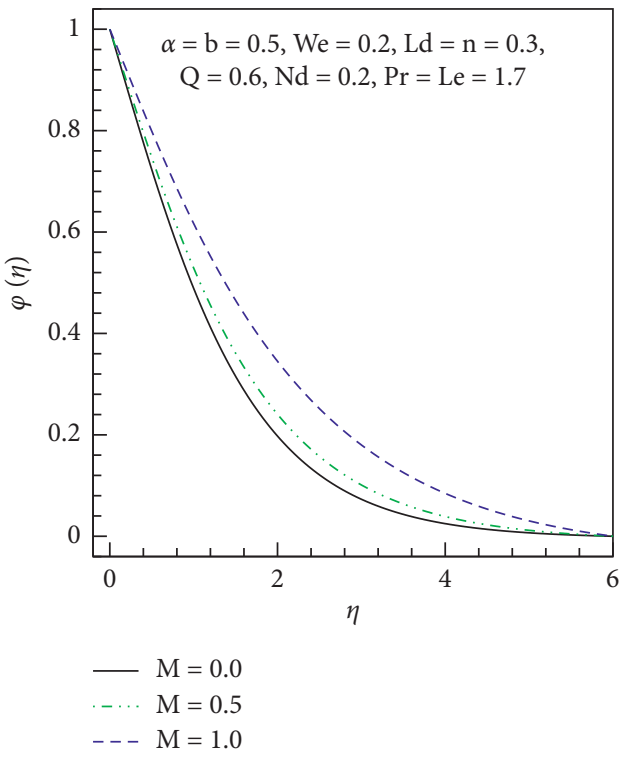

(b)

Figure 6: Variations in concentration profiles for $\alpha$ and $M$.

Figure 8(a). The variations in local Nusselt number against Le for distinct values of $Q$ are shown in Figure 8(b). It is same qualitatively as of Figure 8(a). Further, it is observed that $\mathrm{Ld}$ and $\alpha$ have opposite behavior on the local Nusselt number as illustrated in Figure 8(c). The decreasing behavior of heat transfer rate with increase in $n$ and $b$ is highlighted in Figure 8(d).
Sherwood number reduces with increasing values of $\mathrm{Nd}$ and $\operatorname{Pr}$ as depicted in Figure 9(a). Figure 9(b) shows that Sherwood number enhances for $b$ and Le whereas reduces for $\alpha$ and $M$ as shown in Figure 9(c). Sherwood number with Dufour-solutal Lewis number for distinct values of $n$ is shown in Figure 9(c). Moreover, the qualitative behavior of Figures 9(d) and $9(\mathrm{c})$ is similar. 


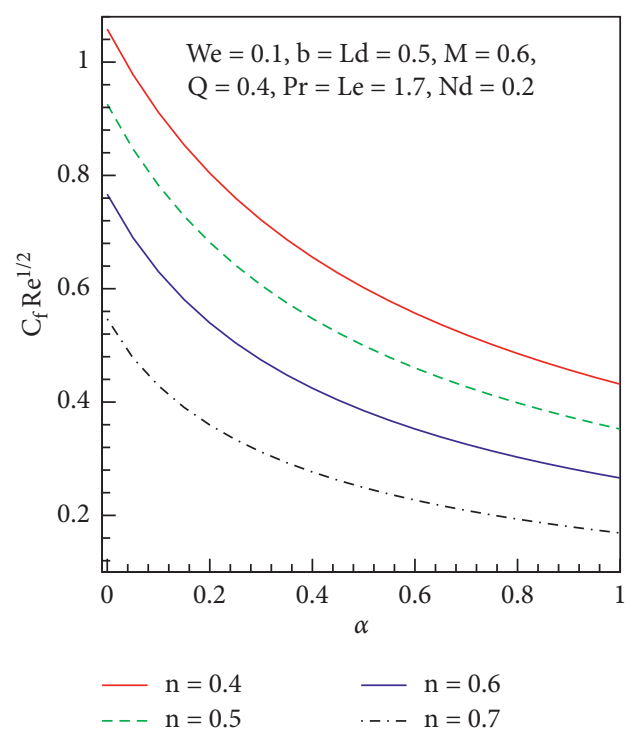

(a)

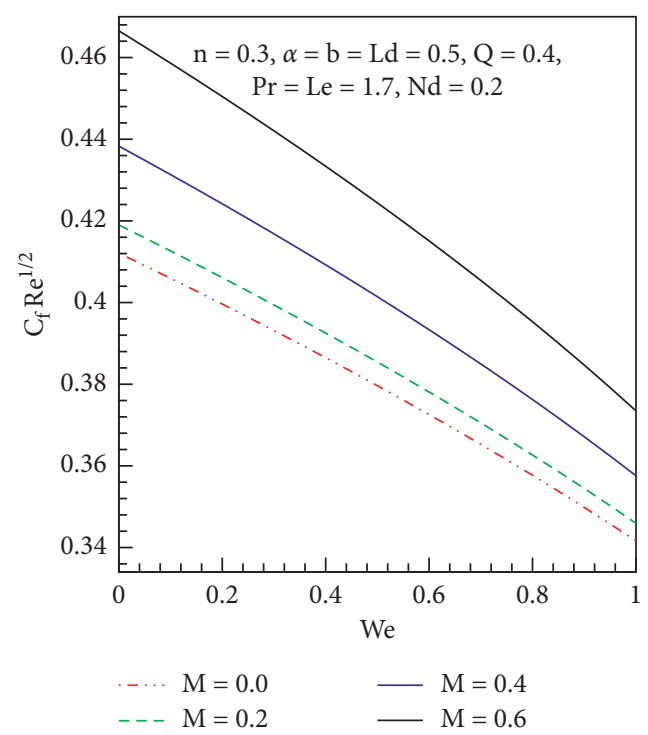

(b)

FIGURE 7: Influence of governing parameters on skin friction coefficient.

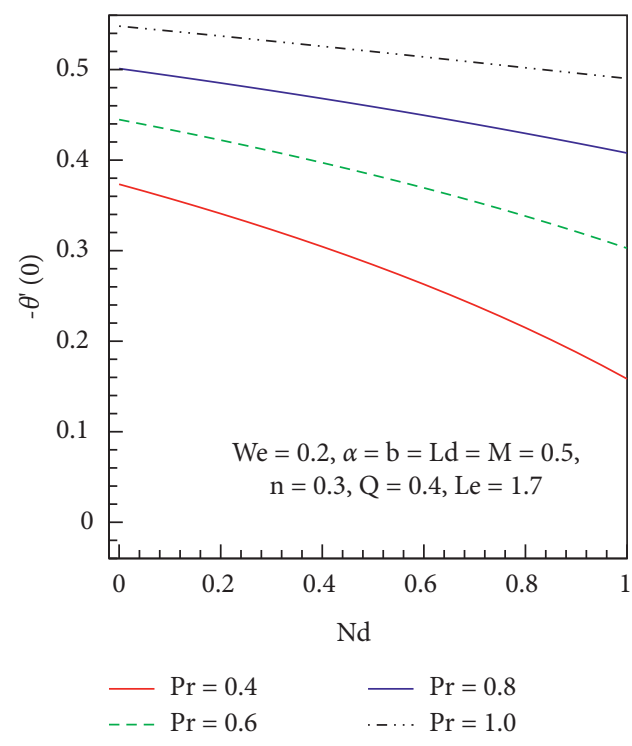

(a)

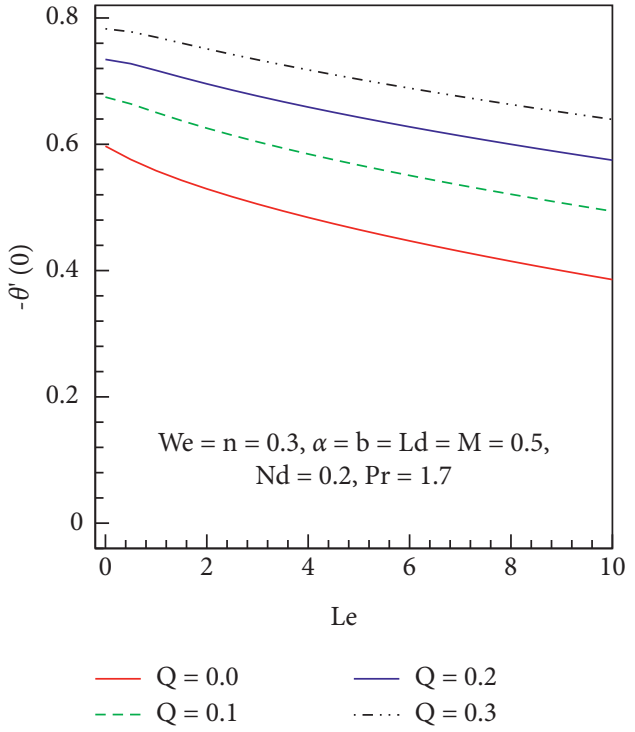

(b)

Figure 8: Continued. 


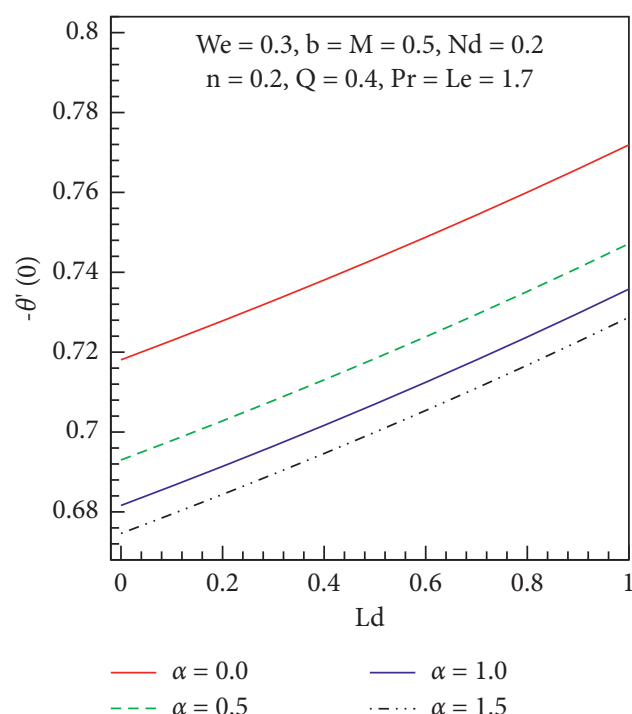

(c)

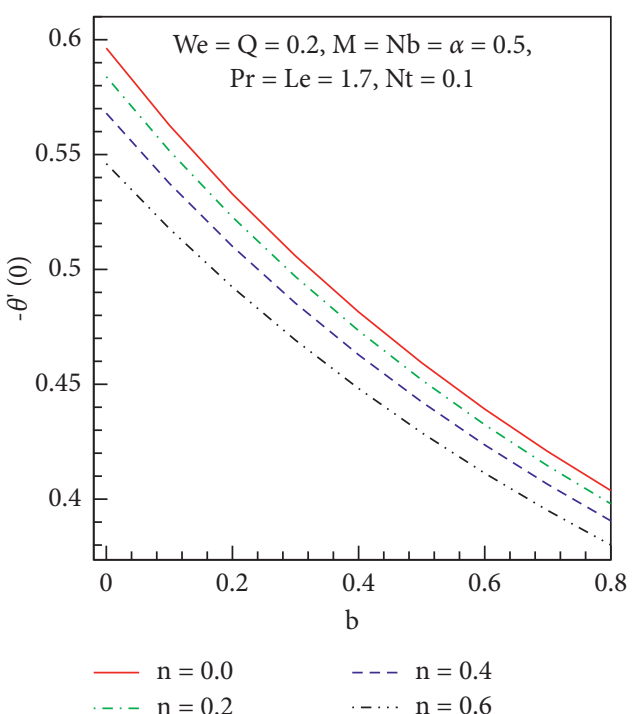

(d)

FigURE 8: Influence of several parameters on local Nusselt numbers.
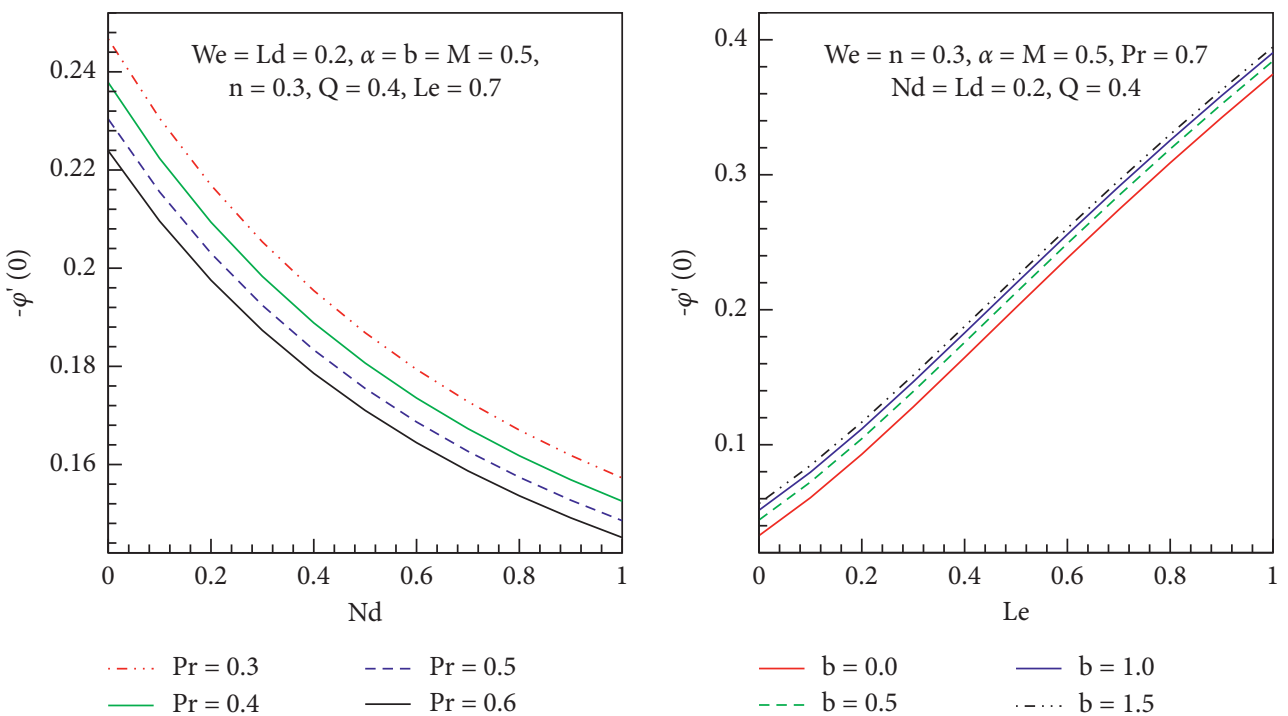

(a)

(b)

FIgURE 9: Continued. 


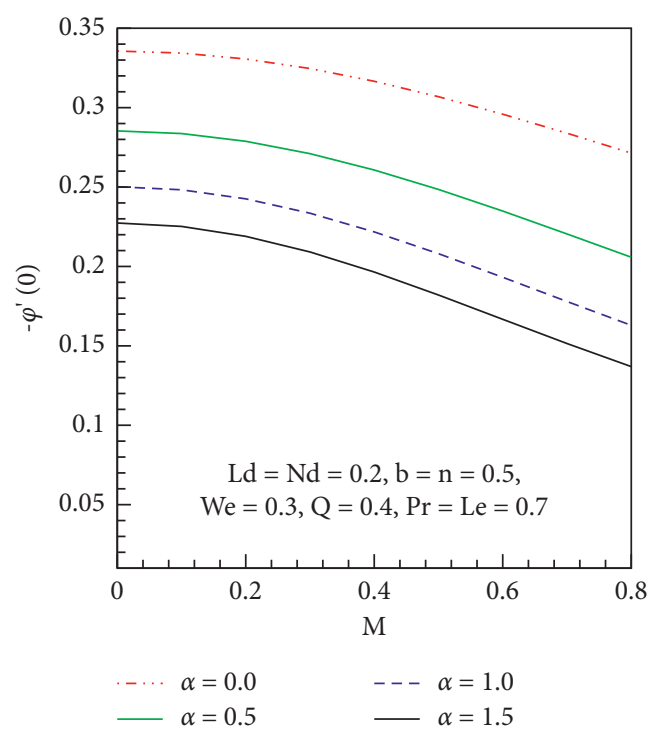

(c)

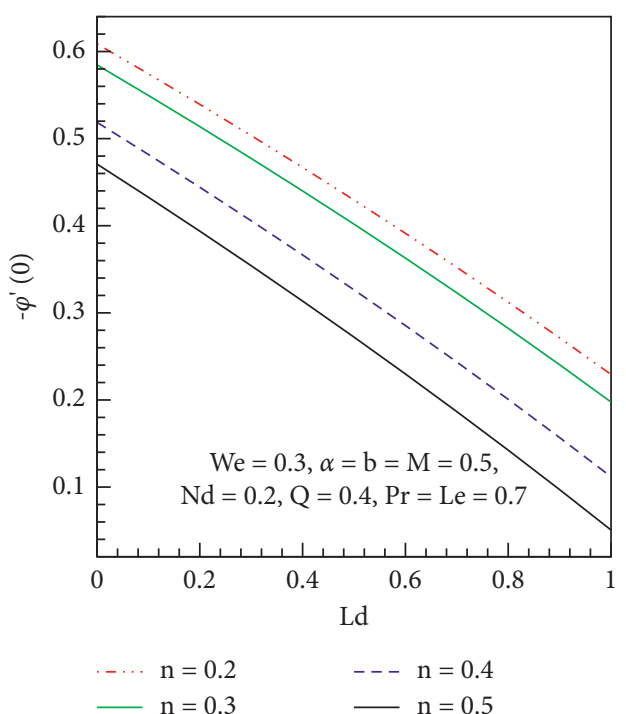

(d)

FIGURE 9: Influence of several parameters on Sherwood number.

\section{Conclusion}

We presented numerical solutions for the double diffusive MHD hyperbolic tangent fluid flow model by developing similarity transformations through implementing Lie group procedure. The transformed nonlinear ODEs solution is then obtained by utilizing the Shooting method. Furthermore, we conclude the present study with the following remarks:

(i) Intensity in the flow for governing parameters including velocity slip, Hartmann number, Weissenberg number, and power law index causes the velocity to decrease

(ii) The temperature profile reduces for enhancing values of Prandtl number, thermal slip, source/ sink, and Dufour parameter

(iii) The power law index, modified Dufour, and velocity slip parameters show similar behavior on temperature function $\theta(\eta)$

(iv) Enhancement of the concentration profile is observed for increasing power law index, thermophoresis parameter, Hartmann number, and velocity slip

(v) Increasing Lewis number has reducing effect on concentration profile

(vi) Reduction in skin friction coefficient shows less resistance to the flow for velocity slip parameter, Weissenberg number, and power law index but opposite behavior for the Hartmann number

(vii) The local Nusselt number of the flow shows increasing behavior for source/sink parameter, Prandtl number, and Dufour-solutal Lewis number whereas decreasing behavior for power law index, modified Dufour parameter, Lewis number, and slip parameters (viii) The thermal slip parameter and Lewis number enhance the Sherwood number whereas they reduce the power law index, Dufour parameter, Prandtl number, Dufour-solutal Lewis number, velocity slip parameter, and Hartmann number

\section{Data Availability}

No data were required to perform this research.

\section{Conflicts of Interest}

The authors declare that there are no conflicts of interest.

\section{References}

[1] B. C. Sakiadis, "Boundary-layer behavior on continuous solid surfaces: I. boundary-layer equations for two-dimensional and axisymmetric flow," AIChE Journal, vol. 7, no. 1, pp. 26-28, 1961.

[2] L. J. Crane, "Flow past a stretching plate," Zeitschrift für angewandte Mathematik und Physik ZAMP, vol. 21, no. 4, pp. 645-647, 1970.

[3] K. B. Pavlov, "Magnetohydrodynamic flow of an incompressible viscous fluid caused by deformation of a plane surface," Magnitnaya Gidrodinamika, vol. 4, no. 1, pp. 146-147, 1974.

[4] C. Y. Wang, "Flow due to a stretching boundary with partial slip an exact solution of the Navier+Stokes equations," Chem. Eng. Sci.vol. 57, no. 17, pp. 3745-3747, 2002.

[5] R. Nazar, N. Amin, D. Filip, and I. Pop, "Unsteady boundary layer flow in the region of the stagnation point on a stretching sheet," International Journal of Engineering Science, vol. 42, no. 11-12, pp. 1241-1253, 2004.

[6] M. K. Partha, P. V. S. N. Murthy, and G. P. Rajasekhar, "Effect of viscous dissipation on the mixed convection heat transfer from an exponentially stretching surface," Heat and Mass Transfer, vol. 41, no. 4, pp. 360-366, 2005. 
[7] S. Nadeem, A. Hussain, and M. Khan, "Ham solutions for boundary layer flow in the region of the stagnation point towards a stretching sheet," Communications in Nonlinear Science and Numerical Simulation, vol. 15, no. 3, pp. 475-481, 2010.

[8] T. Hayat, M. Qasim, and S. Mesloub, "MHD flow and heat transfer over permeable stretching sheet with slip conditions," International Journal for Numerical Methods in Fluids, vol. 66, no. 8, pp. 963-975, 2011.

[9] A. Ishak, R. Nazar, and I. Pop, "Magnetohydrodynamic (mhd) flow and heat transfer due to a stretching cylinder," Energy Conversion and Management, vol. 49, no. 11, pp. 3265-3269, 2008.

[10] S. Mukhopadhyay, "MHD boundary layer slip flow along a stretching cylinder," Ain Shams Engineering Journal, vol. 4, no. 2, pp. 317-324, 2013.

[11] K. Zaimi and A. Ishak, "Stagnation-point flow towards a stretching vertical sheet with slip effects," Mathematics, vol. 4, no. 2, p. 27, 2016.

[12] V. U. Bhojappa and S. Zeb, "Oham simulation of 3d transverse magnetic field in rotating flow of Maxwell nanofluid over a stretching sheet with chemical reaction and heat source/sink," Heat Transfer, vol. 50, 2021.

[13] M. Qasim, Z. H. Khan, W. A. Khan, and I. Ali Shah, "MHD boundary layer slip flow and heat transfer of ferrofluid along a stretching cylinder with prescribed heat flux," PLoS One, vol. 9, no. 1, Article ID e83930, 2014.

[14] M. Khan, M. Y. Malik, T. Salahuddin, R. Ku, M. Naseer, and I. Khan, "MHD flow of williamson nanofluid over a cone and plate with chemically reactive species," Journal of Molecular Liquids, vol. 231, pp. 580-588, 2017.

[15] M. Y. Malik, S. Bilal, and M. Bibi, "Numerical analysis for MHD thermal and solutal stratified stagnation point flow of powell-eyring fluid induced by cylindrical surface with dual convection and heat generation effects," Results in Physics, vol. 7, pp. 482-492, 2017.

[16] K. Ur Rehman, A. Qaiser, M. Y. Malik, and U. Ali, "Numerical communication for MHD thermally stratified dual convection flow of casson fluid yields by stretching cylinder," Chinese Journal of Physics, vol. 55, no. 4, pp. 1605-1614, 2017.

[17] K. Ur Rehman, M. Y. Malik, M. Zahri, and M. Tahir, "Numerical analysis of MHD casson Navier's slip nanofluid flow yield by rigid rotating disk," Results in Physics, vol. 8, pp. 744-751, 2018.

[18] S. Nadeem and S. Akram, "Peristaltic transport of a hyperbolic tangent fluid model in an asymmetric channel," Zeitschrift für Naturforschung A, vol. 64, no. 9-10, pp. 559-567, 2009.

[19] A. J. Friedman, S. J. Dyke, and B. M. Phillips, "Over-driven control for large-scale MR dampers," Smart Materials and Structures, vol. 22, no. 4, 2013.

[20] S. Nadeem and E. N. Maraj, "The mathematical analysis for peristaltic flow of hyperbolic tangent fluid in a curved channel," Communications in Theoretical Physics, vol. 59, no. 6, pp. 729-736, 2013.

[21] S. N. Noreen Sher Akbar, R. Ul Haq, and Z. H. Khan, "Numerical solutions of magnetohydrodynamic boundary layer flow of tangent hyperbolic fluid towards a stretching sheet," Indian Journal of Physics, vol. 87, no. 11, pp. 1121-1124, 2013.

[22] M. Naseer, M. Y. Malik, S. Nadeem, and Abdul Rehman, "The boundary layer flow of hyperbolic tangent fluid over a vertical exponentially stretching cylinder," Alexandria Engineering Journal, vol. 53, no. 3, pp. 747-750, 2014.

[23] E. Azhar, Z. Iqbal, E. N. Maraj, and B. Ahmad, "Influence of cattaneo-christov heat flux model on mhd hyperbolic tangent fluid over a moving porous surface," Frontiers in Heat and Mass Transfer (FHMT), vol. 8, 2017.

[24] T. Salahuddin, M. Y. Malik, A. Hussain, M. Awais, I. Khan, and M. Khan, "Analysis of tangent hyperbolic nanofluid impinging on a stretching cylinder near the stagnation point," Results in Physics, vol. 7, pp. 426-434, 2017.

[25] T. H. Noreen Sher Akbar, S. Nadeem, and S. Obaidat, "Peristaltic flow of a tangent hyperbolic fluid in an inclined asymmetric channel with slip and heat transfer," Progress in Computational Fluid Dynamics, an International Journal, vol. 12, no. 5, pp. 363-374, 2012.

[26] T. Hayat, S. Qayyum, A. Ahmed, and S. Ali Shehzad, "Nonlinear thermal radiation aspects in stagnation point flow of tangent hyperbolic nanofluid with double diffusive convection," Journal of Molecular Liquids, vol. 223, pp. 969-978, 2016.

[27] K. Ur Rehman, A. S. Alshomrani, M. Y. Malik, I. Zehra, and M. Naseer, "Thermo-physical aspects in tangent hyperbolic fluid flow regime: a short communication," Case Studies in Thermal Engineering, vol. 12, pp. 203-212, 2018.

[28] Z. Ullah, G. Zaman, and A. Ishak, "Magnetohydrodynamic tangent hyperbolic fluid flow past a stretching sheet," Chinese Journal of Physics, vol. 66, pp. 258-268, 2020.

[29] S. Lie and M. Ackerman, Sophus Lie's 1884 Differential Invariant Paper, Math. Sci. Press, Berkeley, California, 1976.

[30] M. Pakdemirli and M. Yurusoy, "Similarity transformations for partial differential equations," SIAM Review, vol. 40, no. 1, pp. 96-101, 1998.

[31] A. A. Avramenko, S. G. Kobzar, I. V. Shevchuk, A. V. Kuznetsov, and L. T. Iwanisov, "Symmetry of turbulent boundary-layer flows: investigation of different eddy viscosity models," Acta Mechanica, vol. 151, no. 1-2, pp. 1-14, 2001.

[32] A. V. Kuznetsov, A. A. Avramenko, and P. Geng, "Analytical investigation of a falling plume caused by bioconvection of oxytactic bacteria in a fluid saturated porous medium," International Journal of Engineering Science, vol. 42, no. 5-6, pp. 557-569, 2004.

[33] G. Bluman and S. Anco, Symmetry and Integration Methods for Differential Equations, Springer Science and Business Media, New York, 2008.

[34] M. Jalil, S. Asghar, and M. Mushtaq, "Lie group analysis of mixed convection flow with mass transfer over a stretching surface with suction or injection," Mathematical Problems in Engineering, vol. 2010, no. 1-14, 14 pages, Article ID 264901, 2010.

[35] M. Hamad, M. J. Uddin, and A. M. Ismail, "Radiation effects on heat and mass transfer in mhd stagnation-point flow over a permeable flat plate with thermal convective surface boundary condition, temperature dependent viscosity and thermal conductivity," Nuclear Engineering and Design, vol. 242, pp. 194-200, 2012.

[36] A. Aziz, M. J. Uddin, M. A. A. Hamad, and M. Ismail, "MHD flow over an inclined radiating plate with the temperaturedependent thermal conductivity, variable reactive index, and heat generation," Heat Transfer - Asian Research, vol. 41, no. 3, pp. 241-259, 2012.

[37] R. Kandasamy, I. Muhaimin, and N. S. Amin, "Lie group analysis for the effect of temperature-dependent fluid viscosity with thermophoresis on magnetohydrodynamic free convective heat and mass transfer over a porous stretching surface," International Journal of Computational Fluid Dynamics, vol. 24, no. 1-2, 2010.

[38] M. M. Rashidi, E. Momoniat, M. Ferdows, and A. Basiriparsa, "Lie group solution for free convective flow of a nanofluid past a chemically reacting horizontal plate in a porous media," 
Mathematical Problems in Engineering, vol. 2014, Article ID 239082, 21 pages, 2014.

[39] Z. Ullah and G. Zaman, "Lie group analysis of magnetohydrodynamic tangent hyperbolic fluid flow towards a stretching sheet with slip conditions," Heliyon, vol. 3, no. 11, Article ID e00443, 2017.

[40] S. Ahmad, M. Yousaf, A. Khan, and G. Zaman, "Magnetohydrodynamic fluid flow and heat transfer over a shrinking sheet under the influence of thermal slip," Heliyon, vol. 4, no. 10, Article ID e00828, 2018.

[41] S. Nadeem and N. S. Akbar, "Series solutions for the peristaltic flow of a tangent hyperbolic fluid in a uniform inclined tube," Zeitschrift Für Naturforschung A, vol. 65, no. 11, pp. 887-895, 2010.

[42] N. Akbar, S. Nadeem, and W. A. Khan, "Double-diffusive natural convective boundary-layer flow of a nanofluid over a stretching sheet with magnetic field," International Journal of Numerical Methods for Heat and Fluid Flow, vol. 26, 2016. 